\title{
Preschool asthma after bronchiolitis in infancy
}

\author{
P. Koponen*, M. Helminen*, M. Paassilta* , T. Luukkaala" and M. Korppi*
}

ABSTRACT: Asthma risk is lower after wheezing associated with respiratory syncytial virus (RSV) than with non-RSV infection in infancy. RSV is the main wheezing-associated virus in infants aged $<6$ months. We evaluated the outcome of children hospitalised for bronchiolitis at $<6$ months of age, with special focus on viral aetiology and early risk factors.

Out of 205 infants hospitalised for bronchiolitis at $<6$ months of age, $127(62 \%)$ attended a control visit at a mean age of $6.5 \mathrm{yrs}$ and the parents of an additional 39 children were interviewed by telephone. Thus, follow-up data collected by identical structured questionnaires were available from $166(81 \%)$ children. Viral aetiology of bronchiolitis, studied on admission by antigen detection or PCR, was demonstrable in $97 \%$ of cases.

Current asthma was present in 21 (12.7\%) children: $8.2 \%$ in the 110 former RSV patients versus $24 \%$ in non-RSV patients $(p=0.01) .45(27 \%)$ children had ever had asthma. In adjusted analyses, atopic dermatitis, non-RSV bronchiolitis and maternal asthma were independently significant early-life risk factors for asthma.

The risk of asthma was lower after RSV bronchiolitis than after bronchiolitis caused by other viruses in children hospitalised at $<6$ months of age.

KEYWORDS: Asthma, atopy, bronchiolitis, respiratory syncytial virus, rhinovirus

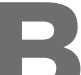
ronchiolitis is the most common lower respiratory infection (LRI) in infancy [1]. The American Academy of Paediatrics has defined bronchiolitis as a disorder in children aged $<24$ months caused by viral LRI and characterised by acute inflammation, mucus production and bronchospasm of small airways [2]. In most European countries, the upper age limit used, at least in clinical practice, has been 12 months [3]. The severity of bronchiolitis and need for hospital care decrease with increasing age [4]. The viral aetiology of bronchiolitis is age-dependent; respiratory syncytial virus (RSV) is the predominant virus at $<6$ months and rhinovirus at $>12$ months of age [5]. Bronchiolitis in infancy increases the asthma risk in later life [6-8]. Studies with outcome data available beyond age 5 yrs have been performed in children aged $<36$ months $[5,9,10],<24$ months $[11,12]$ or $<12$ months $[13,14]$ on admission; however, there are no age-specific data available for children hospitalised at $<6$ months of age.

We prospectively followed up a group of children hospitalised for bronchiolitis at $<6$ months of age in 2001-2002 and 2002-2004 [15, 16]. RSV was the causative agent in $70 \%$, rhinovirus in $7 \%$ and other viruses in $7 \%$ of the cases [15]. When the children were 5-6 yrs of age, they were invited to a clinical follow-up study in 2008-2009. The hypotheses of the study were that asthma is more common after non-RSV bronchiolitis (especially after rhinovirus bronchiolitis) than after RSV bronchiolitis, and more common after bronchiolitis at $<3$ months than at 3-6 months of age.

The aim of the present study was to evaluate the outcome with special focus on asthma at preschool age after hospitalisation for RSV, non-RSV and rhinovirus bronchiolitis at $<6$ months of age. In addition, the age at admission for bronchiolitis and other early risk factors, such as asthma and atopy in parents and atopic dermatitis in children, were analysed as predictors of childhood asthma.

\section{MATERIALS AND METHODS}

205 healthy, full-term infants aged $<6$ months and hospitalised for bronchiolitis at the Dept of Paediatrics, Tampere University Hospital (Tampere, Finland) were enrolled in the study between December 1, 2001 and May 31, 2002 and between October 28, 2002 and May 31, 2004. The Ethics Committee of the Tampere University Hospital District approved the study. Informed consent was obtained from parents before enrolling the children.

Bronchiolitis was characterised by LRI with rhinitis, cough and diffuse wheezes or crackles [15]. The aetiology of bronchiolitis was assessed in nasopharyngeal aspirates by immunofluorescence for
AFFILIATIONS

*Paediatric Research Centre,

${ }^{*}$ Allergy Centre, Tampere University and University Hospital, and - Science Centre, School of Health Sciences, Tampere University, Tampere, Finland.

CORRESPONDENCE

P. Koponen

Tampere University Hospital

Teiskontie 35

33521 Tampere

Finland

E-mail: petri.koponen@uta.fi

Received:

March 052011

Accepted after revision:

May 152011

First published online:

June 232011

European Respiratory Journal

Print ISSN 0903-1936

Online ISSN 1399-3003 
seven viruses, including RSV, by PCR for nine viruses, including RSV and rhinoviruses, and by PCR for Bordetella pertussis [17].

From 2008 to 2009,127 (62\%) children attended the study visit at 5-7 yrs of age. In addition, parents of the 39 children who did not attend the study visit were contacted and interviewed by telephone. Thus, follow-up data collected by identical structured questionnaires were available from 166 (81\%) children (fig. 1). Doctor-diagnosed asthma, the age when asthma was diagnosed and the continuous or intermittent use of inhaled corticosteroids (ICS) as maintenance medication for asthma were recorded by year. Intermittent ICS medication means a pre-set, regular use during infections or respiratory symptoms. In addition, data were recorded on parent-reported wheezing episodes and episodes of other asthma-like symptoms, such as prolonged $(>4$ weeks) cough and night cough apart from infection. The presence of doctor-diagnosed atopic dermatitis and allergic rhinitis was recorded; only cases who were symptomatic during the preceding 12 months were included. In addition, parental doctor-diagnosed asthma and atopy (allergic rhinitis or atopic dermatitis), keeping of indoor furred pets, and parental smoking during and after pregnancy were surveyed. All data were collected separately for mothers and fathers.

Skin-prick tests (SPTs) were performed in 124 children for eight allergens: birch, timothy grass and mugwort pollens, cat and dog dander, house dust mites (Dermatophagoides pteronyssimus and D. farinae) and spores of the mould Alternaria alternata. Wheals with a mean diameter of $\geqslant 3 \mathrm{~mm}$ were regarded as positive. Children were not allowed to take any antihistamine medication for 5 days before testing.

Bronchial hyperresponsiveness (BHR) was studied by exercise challenge test (ECT), which consisted of free running outdoors for $8 \mathrm{~min}$ and measurements of pre- and post-exercise airway resistance by impulse oscillometry (IOS) (Master Screen IOS; Jaeger, Höchberg, Germany). Exercise was considered sufficient when heart rate, monitored using a heart rate monitor (Polar Ltd, Kempele, Finland), was $\geqslant 90 \%$ of the predicted maximum for $\geqslant 2 \mathrm{~min}$. IOS was repeated until three acceptable pre-exercise and two acceptable post-exercise curves were

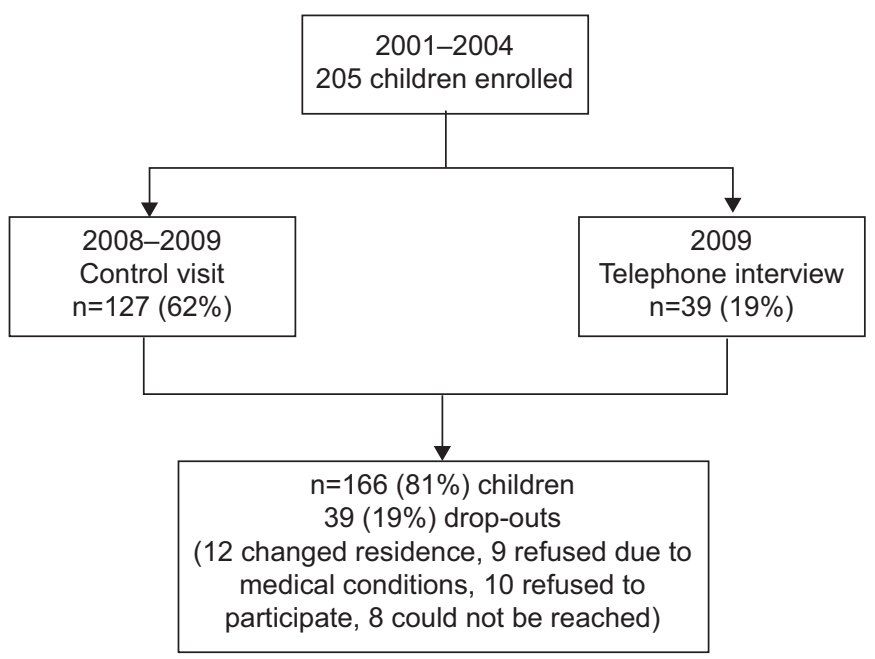

FIGURE 1. Flow chart of the study population. obtained. The resistance curves had to be graphically appropriate and free from artefacts for the whole 30-s measurement time. Resistance values were measured at the $5-\mathrm{Hz}$ level (total respiratory resistance at $5 \mathrm{~Hz}(\operatorname{Rrs} 5)$ ) and expressed as standard deviations from national height-related, sex-specific references [18]. BHR was considered to be present if the best post-exercise Rrs5 value had increased $\geqslant 35 \%$ from the best pre-exercise value [19]. If the child had suffered from an infection during the two preceding weeks, IOS was rescheduled.

Current asthma was considered to be present if the child was on continuous maintenance medication for asthma, or if the child had suffered from doctor-diagnosed wheezing or prolonged ( $>4$ weeks) cough or night cough, apart from infection, during the preceding 12 months, and BHR was documented in ECT. Previous asthma before the control visit was defined by the use of ICS as continuous or intermittent maintenance medication for asthma. If the child had either previous or current asthma, the term "asthma ever in life" was used.

\section{Statistics}

The data were analysed using SPSS 18.0 (IBM, Helsinki, Finland). The statistical significances of differences between the groups were calculated with the unpaired t-test, Chi-squared test and Fisher's exact test. Logistic regression was used to analyse the associations between risk factors and asthma, first by univariate analyses and then by multivariate analyses adjusted for age on admission ( $<3$ versus $>3$ months), sex and characteristics which were significant in univariate analyses. Odds ratios with $95 \%$ confidence intervals are reported from both univariate (OR) and multivariate adjusted (aOR) analyses.

\section{RESULTS}

The mean \pm SD age of the 166 children attending the study was $6.5 \pm 0.57 \mathrm{yrs}$ and $86(52 \%)$ were male. Current asthma was present in $21(12.7 \%)$ children: in 14 males (16.3\% of males; $\mathrm{p}=0.05$ versus females) and in seven females ( $8.8 \%$ of females). In addition, there were 24 children with no current asthma who had been previously, but not during the preceding 12 months, taking ICS as maintenance medication for asthma. Thus, the number of children with asthma ever in life before or during the study was $45(27 \%)$. The age-specific prevalence and cumulative incidence of asthma, defined by the use of continuous or intermittent ICS, are presented in figure 2 . The highest prevalence, $26.9 \%$, was seen at $2-3$ yrs of age.

18 children with current asthma had used ICS during the preceding 12 months. 12 children were on continuous and six on intermittent ICS, and two of them also used leukotriene antagonists. Five $(24 \%)$ children were symptomatic and six (29\%) hyperresponsive in ECT despite maintenance medication. Three additional children had symptoms consistent with asthma and were hyperresponsive in ECT, and they were defined to have asthma. BHR was documented in five other children, but none of them reported doctor-diagnosed wheezing or prolonged or night cough. Six $(4 \%)$ of the nonasthmatic children had suffered from repeated parent-reported wheezing, but none of them reported doctor-diagnosed wheezing, prolonged or night cough, or had BHR in ECT.

RSV had caused 117 (70.5\%) and rhinovirus 21 (12.7\%) of the 166 bronchiolitis cases (table 1). B. pertussis was involved in $10(6 \%)$ 


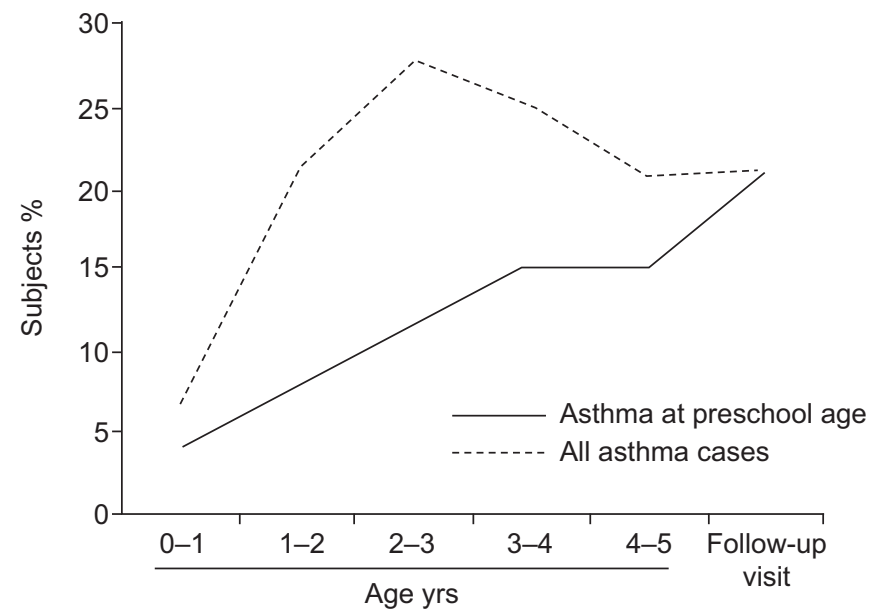

FIGURE 2. The age-specific prevalence and cumulative incidence of asthma, defined by the use of inhaled corticosteroids, in the 166 study subjects.

cases, but all were mixed infections with viruses. Current asthma at $6.5 \mathrm{yrs}$ of age was present in nine $(7.7 \%)$ of former RSV bronchiolitis patients (versus $24.4 \%$ of former non-RSV patients; $\mathrm{p}=0.01)$, in three $(14.3 \%)$ former rhinovirus bronchiolitis patients and in one $(10 \%)$ former B. pertussis-positive patients.

Age on admission as a continuous variable (but not categorised into $<3$ and $>3$ months), atopic dermatitis at $<12$ months of age $(71.4 \%$ versus $23.4 \% ; \mathrm{p}<0.001)$ and asthma in mothers $(38.1 \%$ versus $11.0 \% ; \mathrm{p}=0.001$ ) but not in fathers were significantly associated with current asthma (table 1). Conversely, maternal smoking, paternal smoking and keeping furred pets at home during infancy had no association with later asthma (table 1).

$48(29 \%)$ study children had suffered from symptoms presumptive for allergic rhinitis during the preceding 12 months and 13 $(27 \%)$ of them had current asthma (versus $6.8 \%$ in those 118 with no allergic rhinitis; $\mathrm{p}<0.001$ ). Correspondingly, $61.9 \%$ of the 21 children with and $24.1 \%$ of those 145 without asthma had allergic rhinitis. SPTs were performed in 124 children; eight (53.3\%) out of 15 children with asthma were SPT-positive (versus $6.4 \%$ of those 109 with no asthma; $\mathrm{p}=0.07)$. Birch pollen $(22.8 \%)$, timothy grass pollen (19.2\%), dog dander (12.7\%) and cat dander (11.7\%) were common, and mugwort pollen $(1.0 \%)$, house dust mites $(1.0 \%)$ and spores of moulds $(0 \%)$ were rare allergens.

Maternal history of asthma was a significant risk factor for asthma in children (table 1). However, 21 (87.5\%) out of the 24 mothers with asthma $(\mathrm{p}=<0.001$ versus 52 mothers with no asthma) and six (60\%) out of the 10 fathers with asthma $(p=0.06$ versus 34 fathers with no asthma) also had doctor-diagnosed allergic rhinitis or atopic dermatitis. The association between parental asthma and atopy was so strong that their independent associations with asthma in children could not be studied, and we included only maternal asthma in the multivariate analyses.

As seen in table 2, non-RSV bronchiolitis was an independent risk factor for preschool asthma in multivariate analyses adjusted for age on admission, sex, atopic dermatitis in infancy and maternal asthma (aOR 3.74, 95\% CI 1.28-10.99). Atopic dermatitis in infancy and maternal asthma were other significant risk factors for current asthma in adjusted analyses (table 2).

\begin{tabular}{|c|c|c|c|}
\hline \multirow[t]{2}{*}{ TABLE 1} & \multirow[b]{2}{*}{ Current asthma } & \multirow[b]{2}{*}{ No asthma } & \multirow[b]{2}{*}{ p-value } \\
\hline & & & \\
\hline Subjects $\mathbf{n}$ & 21 & 145 & \\
\hline Age at admission days & $113(63-147)$ & $77(38-118)$ & 0.027 \\
\hline Age at admission months & & & 0.06 \\
\hline$<3$ & $9(42.9)$ & $93(64.1)$ & \\
\hline$>3$ & $12(57.1)$ & $52(35.9)$ & \\
\hline Males & $14(66.7)$ & $72(49.7)$ & 0.145 \\
\hline RSV bronchiolitis & $9(42.9)$ & $108(74.5)$ & 0.015 \\
\hline Non-RSV bronchiolitis ${ }^{\#}$ & $12(57.1)$ & $37(25.5)$ & 0.01 \\
\hline $\begin{array}{l}\text { Atopic dermatitis at }<12 \text { months } \\
\text { of age }\end{array}$ & $15(71.4)$ & $34(23.4)$ & $<0.001$ \\
\hline $\begin{array}{l}\text { Maternal smoking during } \\
\text { pregnancy }\end{array}$ & $1(4.8)$ & $28(19.3)$ & $0.129^{\bullet}$ \\
\hline Maternal history of asthma & $8(38.1)$ & $16(11.0)$ & 0.001 \\
\hline Paternal history of asthma & $0(0.0)$ & $10(6.8)$ & $0.231^{\bullet}$ \\
\hline Maternal history of atopy & $13(61.9)$ & $60(41.4)$ & 0.077 \\
\hline Paternal history of atopy & $8(38.1)$ & $32(22.1)$ & 0.109 \\
\hline Maternal smoking in infancy & $5(23.8)$ & $42(29.0)$ & 0.624 \\
\hline Paternal smoking in infancy & $9(42.9)$ & $61(42.1)$ & 0.946 \\
\hline Furred pet at home in infancy & $5(23.8)$ & $46(31.7)$ & 0.462 \\
\hline \multicolumn{4}{|c|}{$\begin{array}{l}\text { Data are presented as median (interquartile range) or } n(\%) \text {, unless otherwise } \\
\text { stated. The t-test was used for continuous variables and Pearson's Chi-squared } \\
\text { test was used for categorised variables, unless otherwise stated. RSV: } \\
\text { respiratory syncytial virus. \#: rhinovirus in three cases, influenza A virus in } \\
\text { three cases, parainfluenza type } 3 \text { virus in three cases, adenovirus in one case } \\
\text { and human metapneumovirus in one case, and two cases with no viral } \\
\text { aetiology; } ~ \\
\text { : Fisher's exact test. }\end{array}$} \\
\hline
\end{tabular}

The analyses were repeated in the subgroup of 124 children with SPT results available by including SPT positivity in the model. SPT positivity was associated with an increased asthma risk in univariate analyses (OR 3.60, 95\% CI 1.19-10.9) but not in multivariate analyses (aOR 2.81, 95\% CI 0.72-10.9). In these analyses, atopic dermatitis in infancy, non-RSV bronchiolitis and maternal asthma lost statistical significance as risk factors of current asthma (data not shown).

There were no significant differences in baseline characteristics, such as sex, age on admission and viral aetiology of bronchiolitis, between the 166 attendees and the 39 drop-outs (data not shown). Likewise, there were no significant differences in baseline or questionnaire-based characteristics, such as atopy, asthma and smoking in parents, or atopic dermatitis in infancy and allergic rhinitis at preschool age in study children, between those 39 interviewed by telephone and those 127 attending the study visit (data not shown).

\section{DISCUSSION}

There are four main results in the present prospective followup study at preschool age after hospitalisation for bronchiolitis at $<6$ months of age. First, asthma prevalence was only $12.7 \%$ at a mean age of 6.5 yrs. This figure is lower than the previously reported prevalence figures up to $48 \%$ after bronchiolitis in infancy $[11-14,20]$. Secondly, atopic dermatitis in infancy was a 


\begin{tabular}{|c|c|c|c|c|}
\hline \multirow[t]{2}{*}{ TABLE 2} & \multicolumn{4}{|c|}{$\begin{array}{l}\text { Logistic regression: risk factors for asthma at a } \\
\text { mean age of } 6.5 \text { yrs }\end{array}$} \\
\hline & & Subjects & Crude & Multivariate \\
\hline \multicolumn{2}{|c|}{$\begin{array}{l}\text { Age } \geqslant 3 \text { months at } \\
\text { admission }\end{array}$} & 64 & $2.31(0.91-5.85)$ & $2.04(0.69-6.04)$ \\
\hline \multicolumn{2}{|l|}{ Male sex } & 86 & $2.03(0.77-5.32)$ & $2.01(0.64-6.29)$ \\
\hline \multicolumn{2}{|c|}{$\begin{array}{l}\text { Atopic dermatitis at } \\
<12 \text { months of age }\end{array}$} & 49 & $8.16(2.94-22.7)$ & 7.45 (2.45-22.89) \\
\hline \multicolumn{2}{|c|}{ Non-RSV bronchiolitis } & 50 & $4.04(1.57-10.36)$ & $3.74(1.28-10.99)$ \\
\hline \multicolumn{2}{|c|}{$\begin{array}{l}\text { Maternal history of } \\
\text { asthma }\end{array}$} & 24 & $4.96(1.78-13.79)$ & $3.39(1.03-11.24)$ \\
\hline \multicolumn{5}{|c|}{$\begin{array}{l}\text { Data are presented as } n \text { or odds ratio ( } 95 \% \text { confidence interval). } n=166 \text {. } \\
\text { Multivariate analyses were performed and adjusted for age on admission, sex, } \\
\text { atopic dermatitis in infancy, viral aetiology of bronchiolitis and maternal asthma. } \\
\text { RSV: respiratory syncytial virus. }\end{array}$} \\
\hline
\end{tabular}

significant risk factor for asthma, in line with earlier postbronchiolitis studies $[12,21,22]$. Thirdly, asthma in mothers, but not in fathers, was a significant risk factor for asthma. Asthma in mothers was associated more than asthma in other family members with asthma risk in children in birth cohorts [10]. Finally, confirming the study hypothesis, asthma at preschool age was more common after non-RSV bronchiolitis (24\%) than after RSV bronchiolitis (8\%) in infancy. This observation is in line with previous studies after early-life wheezing from Finland and Wisconsin, USA [9, 20, 23], but we were not able to confirm the specific role of rhinovirus aetiology of bronchiolitis as an asthma predictive factor.

The prevalence of preschool asthma has varied from $15 \%$ to $48 \%$ in previous post-bronchiolitis studies [11-14, 20], which means a four- to 10 -fold increase in asthma prevalence compared with nonselected populations [24]. In earlier post-bronchiolitis studies from Finland and Sweden, the prevalence of asthma was $30 \%$ when the infants were hospitalised at $<12$ months of age [13] and $25-47 \%$ when hospitalised at $<24$ months of age [11, 12, 20]. In birth cohort studies, the prevalence figures have been higher (30-60\%) after wheezing in early life, reflecting the inclusion of mild, parent-reported wheezing cases treated at home $[9,10]$. In the present study, after hospitalisation for bronchiolitis at $<6$ months of age, asthma prevalence at preschool age was low $(12.7 \%)$, and even lower (only $8.9 \%$ ) after hospitalisation at $<3$ months of age. In a recent study from Missouri, USA, the cumulative prevalence of parent-reported, doctor-diagnosed asthma by age 6 yrs was as high as $48 \%$ after RSV bronchiolitis at age $<12$ months [14]. The cumulative prevalence in the present study, called asthma ever in life, was not higher than $27 \%$ when only cases treated with ICS were included.

Atopic dermatitis in infancy, parental atopy, parental asthma (especially asthma in mothers) and passive smoking (especially smoking mothers) have been linked with an increased risk for later asthma [13, 20, 21, 25]. In this study, one-third of children with atopic dermatitis presenting during the first year of life had asthma at preschool age. The figure is higher than in earlier post-bronchiolitis studies after hospitalisation at $<24$ months of age, which evidently included children with less severe atopy not presenting in early infancy [12, 20, 22]. Thus, atopy in infancy is an important risk factor for asthma in later life, and invasive RSV infections in infancy may increase, in addition to the risk of asthma, the risk of allergy at early school age $[13,14]$.

A recent post-bronchiolitis study from Sweden stressed the differences in the harmful effects of maternal and paternal smoking [25]. Maternal smoking led to BHR and reduced lung function, whereas paternal smoking increased the risk of active smoking at teen age. Many studies, like the present study, have not been able to confirm the increased asthma risk after in utero or early-life tobacco smoke exposure [13, 21, 23, 26]. A selection bias might have occurred since passive smoking in infancy is a risk factor of bronchiolitis [27]. In the present study, $\sim 30 \%$ of mothers and $\sim 40 \%$ of fathers smoked, which is more than reported in young Finnish females (20\%) and males (30\%) [28].

RSV has been shown to be the predominant virus in bronchiolitis in infants aged $<6$ months and rhinovirus in infants aged $>12$ months [5]. Asthma risk at preschool age after rhinovirus bronchiolitis has been two- to four-fold compared with RSV bronchiolitis $[9,29]$. Consistent with this, only $8.2 \%$ of the former RSV bronchiolitis patients in our study had asthma at preschool age; in fact, the figure was close to $4-6 \%$ asthma prevalence in a nonselected, age-specific population in Finland [24]. Accordingly, non-RSV bronchiolitis was a significant risk factor for preschool asthma, even after adjustment with potential confounding factors. However, no single virus was predominant in the former non-RSV group with current asthma. The mechanisms behind the link from bronchiolitis in infancy to asthma in childhood are not known. Non-RSV bronchiolitis most probably reveals susceptible infants rather than directly causes later asthma $[9,21,29]$. The role of rhinoviruses as an asthma-predicting factor may be age dependent (not seen in bronchiolitis patients aged $<6$ months).

The study of Sigurs et al. [13] is the only post-bronchiolitis follow-up comparable with the present study. In that study, 47 former RSV bronchiolitis patients hospitalised at $<12$ months of age attended the control visit at the median age of $7.5 \mathrm{yrs}$, and $23 \%$ of them had asthma, compared with $3 \%$ in controls. In the present study, asthma prevalence at the mean age of 6.5 yrs was substantially lower, only $8.2 \%$ among 117 children hospitalised for RSV bronchiolitis at $<6$ months of age. In addition, SIGURS et al. [13] reported that $20 \%$ of former RSV bronchiolitis patients were sensitised to inhaled allergens documented by SPTs, compared with $6 \%$ in controls. In our study, former RSV and non-RSV patients had the same SPT positivity rate $(29 \%)$. In the Swedish study, parental asthma was present in $45 \%$ of the infants with bronchiolitis, compared with $20 \%$ in our patients, which may partly explain the differences in outcome at preschool age.

The main strengths of the present post-bronchiolitis study are the prospective design, and large number and homogeneity of the enrolled patients; all were $<6$ months of age, all needed hospital care and 166 children were followed up over 5 yrs. When bronchiolitis is defined as viral LRI with wheezing at $<24$ months of age, which has been the practice in most earlier studies, the study population is more heterogeneous, consisting of patients with bronchiolitis, reactive airway disease and early-onset asthma. 
The main shortcoming of the present study is that populationbased controls were not enrolled. However, the age-specific prevalence of asthma in Finnish children is well known, being $4-6 \%$ at preschool age [24]. In addition, many subgroups were rather small and thus, the study was underpowered to find many obvious associations. Data on atopic dermatitis and family history of asthma and atopy were carefully collected, but no tests were available for allergen-specific immunoglobulin E, eosinophils or eosinophilic markers, which are well-known risk factors of childhood asthma after bronchiolitis [21, 30]. However, later asthma was so rare and atopic dermatitis in infancy was such a strong predictive factor that any additional data on risk factors would not have changed the main conclusions of the study.

In conclusion, asthma prevalence was low (only 12.7\%) at the mean age of 6.5 yrs after hospitalisation for bronchiolitis at $<6$ months of age. In agreement with the study hypothesis, nonRSV aetiology of bronchiolitis was an independently significant risk factor of asthma in adjusted analyses, but in disagreement with the study hypothesis, age $>3$ months compared with age $<3$ months was not.

\section{SUPPORT STATEMENT}

This study was supported by the University Hospital of Tampere and Tampere Tuberculosis Foundation (Tampere, Finland).

\section{STATEMENT OF INTEREST}

None declared.

\section{REFERENCES}

1 Smyth RL, Openshaw PJ. Bronchiolitis. Lancet 2006; 368: 312-322.

2 American Academy of Paediatrics Subcommittee on Diagnosis and Management of Bronchiolitis. Diagnosis and management of bronchiolitis. Paediatrics 2006; 118: 1774-1793.

3 Jartti T, Makela MJ, Vanto T, et al. The link between bronchiolitis and asthma. Infect Dis Clin North Am 2005; 19: 667-689.

4 Damore D, Mansbach JM, Clark S, et al. Prospective multicenter bronchiolitis study: predicting intensive care unit admissions. Acad Emerg Med 2008; 15: 887-894.

5 Jartti T, Lehtinen P, Vuorinen T, et al. Bronchiolitis: age and previous wheezing episodes are linked to viral etiology and atopic characteristics. Pediatr Infect Dis J 2009; 28: 311-317.

6 Wennergren G, Goksor E, Amark M, et al. Asthma symptoms in early childhood - what happened then? J Allergy Clin Immunol 2004; 113: Suppl. 2, S282.

7 Taussig LM, Wright AL, Holberg CJ, et al. Tucson Children's Respiratory Study: 1980 to present. J Allergy Clin Immunol 2003; 111: 661-675.

8 Piippo-Savolainen E, Korppi M. Wheezy babies - wheezy adults? Review on long-term outcome until adulthood after early childhood wheezing. Acta Paediatr 2008; 97: 5-11.

9 Jackson DJ, Gangnon RE, Evans MD, et al. Wheezing rhinovirus illnesses in early life predict asthma development in high-risk children. Am J Respir Crit Care Med 2008; 178: 667-672.

10 Martinez FD, Wright AL, Taussig LM, et al. Asthma and wheezing in the first six years of life. The Group Health Medical Associates. N Engl J Med 1995; 332: 133-138.

11 Kuikka L, Reijonen $\mathrm{T}$, Remes $\mathrm{K}$, et al. Bronchial asthma after early childhood wheezing: a follow-up until 4.5-6 years of age. Acta Paediatr 1994; 83: 744-748.
12 Wennergren G, Hansson S, Engstrom I, et al. Characteristics and prognosis of hospital-treated obstructive bronchitis in children aged less than two years. Acta Paediatr 1992; 81: 40-45.

13 Sigurs N, Bjarnason R, Sigurbergsson F, et al. Respiratory syncytial virus bronchiolitis in infancy is an important risk factor for asthma and allergy at age 7. Am J Respir Crit Care Med 2000; 161: 1501-1507.

14 Castro M, Schweiger T, Yin-Declue $\mathrm{H}$, et al. Cytokine response after severe respiratory syncytial virus bronchiolitis in early life. J Allergy Clin Immunol 2008; 122: 726-733.

15 Helminen M, Nuolivirta K, Virta M, et al. IL-10 gene polymorphism at $-1082 \mathrm{~A} / \mathrm{G}$ is associated with severe rhinovirus bronchiolitis in infants. Pediatr Pulmonol 2008; 43: 391-395.

16 Nuolivirta K, Hurme M, Halkosalo A, et al. Gene polymorphism of IFNG $+874 \mathrm{~T} / \mathrm{A}$ and TLR4 $+896 \mathrm{~A} / \mathrm{G}$ and recurrent infections and wheezing in toddlers with history of bronchiolitis. Pediatr Infect Dis J 2009; 28: 1121-1123.

17 Nuolivirta K, Koponen P, He QM, et al. Bordetella pertussis infection is common in nonvaccinated infants admitted for bronchiolitis. Pediatr Infect Dis J 2010; 29: 1013-1015.

18 Malmberg LP, Pelkonen A, Poussa T, et al. Determinants of respiratory system input impedance and bronchodilator response in healthy Finnish preschool children. Clin Physiol Funct Imaging 2002; 22: 64-71.

19 Malmberg LP, Mäkelä MJ, Mattila PS, et al. Exercise-induced changes in respiratory impedance in young wheezy children and nonatopic controls. Pediatr Pulmonol 2008; 43: 538-544.

20 Kotaniemi-Syrjänen A, Reijonen TM, Korhonen K, et al. Wheezing requiring hospitalization in early childhood: predictive factors for asthma in a six-year follow-up. Paediatr Allergy Immunol 2002; 13: 418-425.

21 Hyvärinen M, Piippo-Savolainen E, Korhonen K, et al. Teenage asthma after severe infantile bronchiolitis or pneumonia. Acta Paediatr 2005; 94: 1378-1383.

22 Heymann PW, Carper HT, Murphy DD, et al. Viral infections in relation to age, atopy, and season of admission among children hospitalised for wheezing. J Allergy Clin Immunol 2004; 114: 239-247.

23 Reijonen TM, Kotaniemi-Syrjänen A, Korhonen K, et al. Predictors of asthma three years after hospital admission for wheezing in infancy. Paediatrics 2000; 106: 1406-1412.

24 Remes ST, Korppi M, Remes K, et al. Prevalence of asthma at school age: a clinical population-based study in eastern Finland. Acta Paediatr 1996; 85: 59-63.

25 Goksor E, Amark M, Alm B, et al. The impact of pre- and postnatal smoke exposure on future asthma and bronchial hyperresponsiveness: 142. Allergy 2007; 62: Suppl. 83, 58.

26 Holberg CJ, Wright AL, Martinez FD, et al. Risk factors for respiratory syncytial virus-associated lower respiratory illnesses in the first year of life. Am J Epidemiol 1991; 133: 1135-1151.

27 Carroll KN, Gebretsadik T, Griffin MR, et al. Maternal asthma and maternal smoking are associated with increased risk of bronchiolitis during infancy. Paediatrics 2007; 119: 1104-1112.

28 Heloma A, Nurminen M, Reijula K, et al. Smoking prevalence, smoking-related lung diseases, and national tobacco control legislation. Chest 2004; 126: 1825-1831.

29 Kotaniemi-Syrjanen A, Vainionpaa R, Reijonen TM, et al. Rhinovirusinduced wheezing in infancy - the first sign of childhood asthma? J Allergy Clin Immunol 2003; 111: 66-71.

30 Halonen M, Stern D, Taussig LM, et al. The predictive relationship between serum IgE levels at birth and subsequent incidences of lower respiratory illnesses and eczema in infants. Am Rev Respir Dis 1992; 146: 866-870. 